American Journal of Pediatrics
2017;3(3): 13-17
http://www.sciencepublishinggroup.com/j/ajp
doi: 10.11648 /j.ajp.20170303.11
ISSN: $2472-0887$ (Print); ISSN: $2472-0909$ (Online)

\title{
Malaria in the New-born as Seen at the University of Port Harcourt Teaching Hospital: A Retrospective Review
}

\author{
Yaguo-Ide Lucy Eberechukwu ${ }^{1}$, Awopeju Abimbola Temitayo Oluwajenyo ${ }^{2}$ \\ ${ }^{1}$ Department of Paediatrics and Child Health, University of Port Harcourt Teaching Hospital, Port Harcourt, Nigeria \\ ${ }^{2}$ Department of Medical Microbiology and Parasitology, University of Port Harcourt Teaching Hospital, Port Harcourt, Nigeria
}

\section{Email address:}

lucyaguolucy@gmail.com (Yaguo-Ide L. E.),drawopeju@yahoo.co.uk (Awopeju A. T. O.)

\section{To cite this article:}

Yaguo-Ide Lucy Eberechukwu, Awopeju Abimbola Temitayo Oluwajenyo. Malaria in the New-born as Seen at the University of Port Harcourt Teaching Hospital: A Retrospective Review. American Journal of Pediatrics. Vol. 3, No. 3, 2017, pp. 13-17. doi: 10.11648/j.ajp.20170303.11

Received: May 19, 2017; Accepted: June 26, 2017; Published: August 9, 2017

\begin{abstract}
Malaria has continued to be an endemic disease of the tropics and subtropics. Malaria in the newborn is a global public health challenge with a high mortality rate in developing countries. A descriptive retrospective study over a 5 years period (2006-2011) conducted at the University of Port Harcourt Teaching Hospital. Information on Socio-demographic data, malaria parasite laboratory result and clinical information were retrieved from the medical microbiology departmental result registry. There was an overall $61 \%$ prevalence of malaria in neonates over the five years period with severe malaria occurring in $2.94 \%$ of them. Yearly Prevalence of malaria from 2006 to 2008 was $87.66 \%, 43.83 \%$, and $70.74 \%$ respectively. There was about twelve percent decline in prevalence of malaria between 2009 and 2011 from $69.62 \%$ to $57.78 \%$ The study demonstrated a high prevalence of malaria in newborn in southern Nigeria, necessitating a need for high index of suspicion, early diagnosis, prompt and appropriate treatment to prevent neonatal mortality.
\end{abstract}

Keywords: Newborn, Neonate Malaria Parasitemia Prevalence, Severity, Preventive, Port Harcourt

\section{Introduction}

Malaria is the most important disease caused by protozoa in the tropics. [1] It is caused by the parasite Plasmodium sp. In most cases the parasites are introduced into its host through a bite of an infected female anopheles mosquitos. Less commonly the disease is acquired congenitally through the placenta, through an infected blood transfusion, Perinatally due to mingling of blood during birth and through needle prick injuries. [1] Globally there are over 270 million new cases of malaria every year. [1] Over $80 \%$ of these are in Africa south of the Sahara. Annually there are 1.5-3million deaths from malaria and over $80 \%$ of these deaths are in Africa. [1] P. falciparum is responsible for $80 \%-90 \%$ of the malaria infections either alone or in combination with other species. [1] Repeated infections with the plasmodium results in development of natural immunity against the parasites. In the neonate, there is a passively acquired immunity from transplacental transfer of IgG from the mother to her feotus and this acquired immunity protects the newborn in the first few months of life. [1] Infection with Plasmodium sp is characterized by common symptoms such as headaches, fever, joint pains and vomiting. [2, 3] In the newborn asexual malaria parasite detected in the cord blood or peripheral blood during the first week of life is termed congenital malaria and is due to transmission from the mother through placenta just before or during delivery $[4,5]$ while acquired neonatal malaria, which can occur within the first 28 days of life is due to an infected mosquitos bite after birth. [4, 5] It is difficult to differentiate between congenital and acquired malaria especially in malaria endemic areas like Nigeria [6]. Several studies in Africa have demonstrated that $7-10 \%$ of the newborns may have malaria parasites in their cord blood. [7] Neonatal malaria has been reported to be prevalent in malaria endemic areas such as Nigeria, despite the protective effects of maternal antibodies transferred to the neonate and the protection of the fetal haemoglobin in inhibiting Plasmodium sp development in the newborn [8-10]. Incidence of Neonatal malaria has been reported to range from $6-20 \%$ across Africa [10-13] and from $1.1 \%$ to $5.1 \%$ across Nigeria $[10,13]$ Malaria is a serious health challenge, 
with serious socioeconomic consequences especially in Nigeria which contributes to about one-quarter of the cases in the malaria endemic countries [10]. A retrospective study of malaria in the newborn as documented in medical microbiology registry of the department of medical microbiology and parasitology of the University of Port Harcourt Teaching Hospital from January 2006 to December 2011 was carried out.

\section{Materials and Methods}

\subsection{Study Area}

This study was carried out at the University of Port Harcourt Teaching Hospital (UPTH), Rivers state Nigeria. It is a tertiary health care institution that also attends to referral cases in the Niger-Delta region of Nigeria.

\subsection{Study Population}

All patients suspected of malaria in the neonatal group were included in the study. While patients above 1 month and patients with incomplete data were excluded from the study.

\subsection{Data Collection}

Data of the patients suspected of malaria and recommended for laboratory tests were retrieved from the laboratory records of the department of medical microbiology. Demographic data, results of laboratory tests were collected and analyzed with the statistical package for social sciences (SPSS) v20 (IBM, USA).

\subsection{Data Analysis}

The Chi-square test was used to compare proportion of malaria among the patients according to sex. All tests were carried out at a $95 \%$ confidence interval at a significant $\mathrm{p}$ value of $\leq 0.05$ with the Epi Info v7 software (CDC, USA).

\section{Results and Discussion}

\subsection{Results}

The results showed that the mean age of the patients was $0.25 \pm 0.01$ month. There were $1883(55.55 \%)$ male patients and $1507(44.45 \%)$ female patients as shown in Table 1.

Table 1. Demographic Distribution of Patients.

\begin{tabular}{lll}
\hline Age $($ Mean \pm S. D) & $\mathbf{0 . 2 5} \pm \mathbf{0 . 0 1}$ months & \\
\hline Sex & Frequency & Percent \\
Male & 1883 & $55.55 \%$ \\
Female & 1507 & $44.45 \%$ \\
Total & 3390 & $100.00 \%$ \\
\hline
\end{tabular}

SD: Standard Deviation

Figure 1. Shows that 2074 (61\%) patients were positive for malaria and 1316 (39\%) did not have malaria.

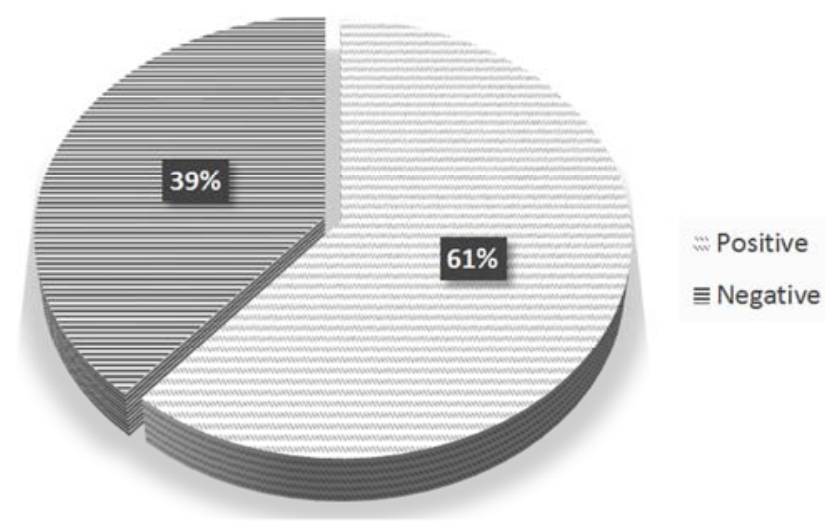

Figure 1. Frequency of Malaria in the Newborn.

Table 2 shows that 1149 male patients were positive for malaria and 734 did not have malaria, while 925 of the female patient had malaria and 582 did not have malaria. There was no significant difference $(\mathrm{p}=0.8304)$ in the occurrence of malaria in the patients.

Table 2. Distribution of malaria according to sex.

\begin{tabular}{llll}
\hline SEX & Positive $(\mathbf{n}, \boldsymbol{\%})$ & Negative $(\mathbf{n}, \mathbf{\%})$ & Chi-square (p-value) \\
\hline Male & $1149(55.40)$ & $734(55.78)$ & \\
Female & $925(44.60)$ & $582(44.22)$ & $0.048(0.8304)^{* *}$ \\
Total & $2074(100.00)$ & $1316(100.0)$ & \\
\hline
\end{tabular}

**Difference is not statistically significant $(\mathrm{p}>0.05)$

Table 3 shows the microscopic grading of malaria parasites in the patients. There were $1664(80.23 \%)$ cases of malaria with $1+, 349(16.83 \%)$ with $2+$ and $60(2.94 \%)$ had $\geq 3+$ parasitemia.

Table 3. Microscopic enumeration of malaria parasite.

\begin{tabular}{lll}
\hline Grading & Frequency (n) & Percent (\%) \\
\hline $1+$ & 1664 & 80.23 \\
$2+$ & 349 & 16.83 \\
$\geq 3+$ & 61 & 2.94 \\
Total & 2074 & $100.00 \%$ \\
\hline
\end{tabular}

Table 4 shows that 1117 (97.21\%) male patients had mild malaria and $32(2.79 \%)$ had severe malaria. Among the female patients $896(96.86 \%)$ had mild malaria and 29 $(3.15 \%)$ had severe malaria. There was no significant difference $\left(\chi^{2}=0.22 ; p=0.6390\right)$ between mild and severe among the patients.

Table 4. Severity of malaria by sex.

\begin{tabular}{llll}
\hline Malaria Grade & Male (n, \%) & Female (n, \%) & $\begin{array}{l}\text { Chi-square } \\
\text { (p-value) }\end{array}$ \\
\hline Mild & $1117(97.21)$ & $896(96.86)$ & 0.22 \\
Severe & $32(2.79)$ & $29(3.14)$ & $(0.6390)^{* *}$ \\
Total & $1149(100.0)$ & $925(100.0)$ & \\
\hline
\end{tabular}

**difference between both groups is not statistically significant $(\mathrm{p}>0.05)$

Among the patients with severe malaria, 30 (49.2\%) had Septicemia, $23(37.7 \%)$ had severe anaemia, $5(8.2 \%)$ and 8 $(13.1 \%)$ other associated symptoms as shown in Table 5. 
Table 5. Severe Malaria and associated Conditions.

\begin{tabular}{lll}
\hline Associated Symptoms & Frequency (n) & Percent (\%) \\
\hline Septicaemia & 30 & 49.2 \\
Severe Anaemia & 23 & 37.7 \\
Others & 8 & 13.1 \\
Total & 61 & 100.0 \\
\hline
\end{tabular}

The prevalence of malaria according to months is as follows: January (60.57\%), February (58.92\%), March (56.61\%), April (72.57\%), May (77.20\%), June (86.32\%), July (67.19\%), August (70.21\%), September (80.0\%), October (52.17\%), November $(51.20 \%)$ and December $(18.03 \%)$ as shown in Figure 2.

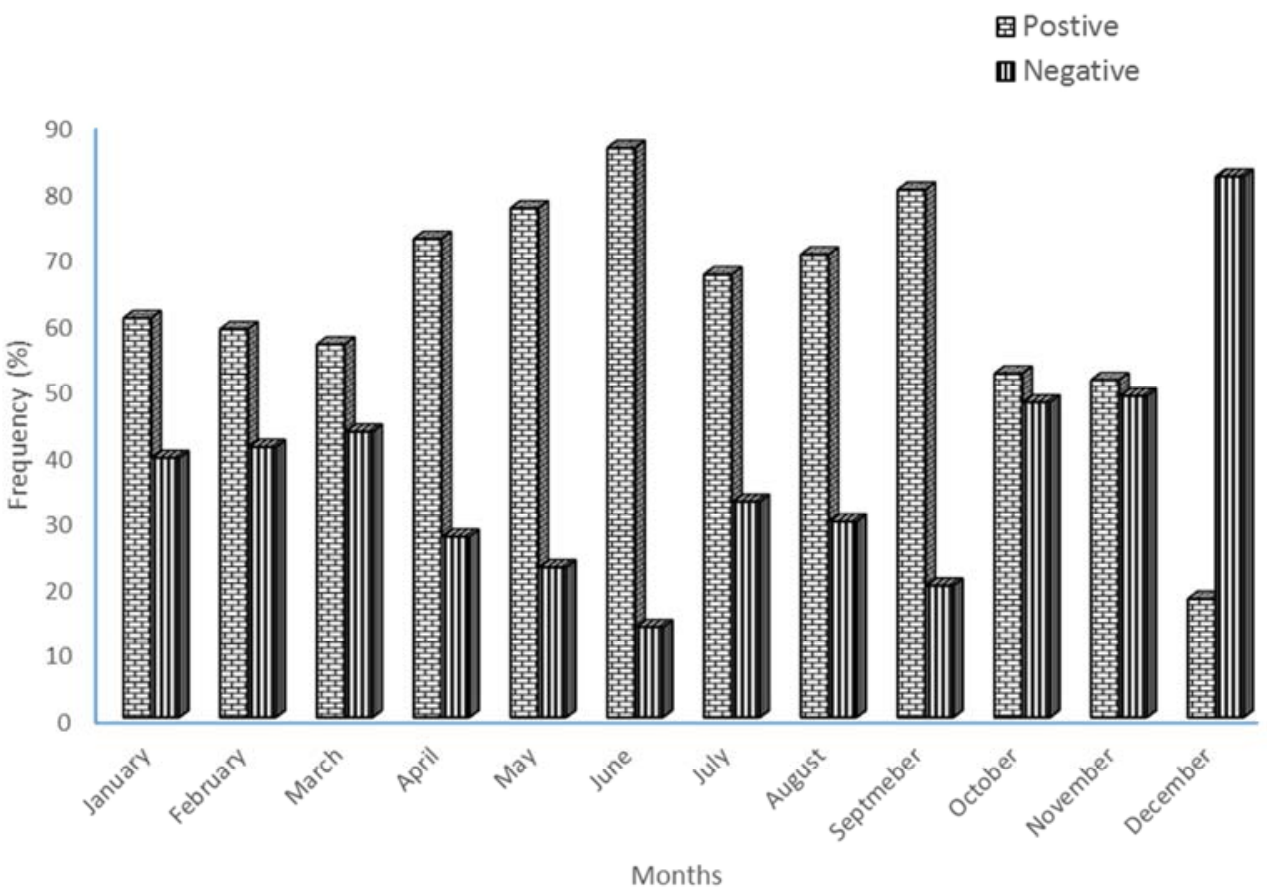

Figure 2. Distribution of Malaria according to months.

The distribution of malaria according to the year showed that there were $419(87.66 \%)$ positive case out of 478 in 2006,636 (43.83\%) positive cases were recorded in 1451 patients in 2007,735 (70.74\%) patients of 1039 were positive for malaria in 2008. In the year 2009, $165(69.62 \%)$ of 237 patients were positive for malaria. In $2010,93(66.43 \%)$ of 140 patients were positive for malaria and in the year 2011, 26 (57.78\%) of the 45 patients were positive for malaria as shown in Figure 3.

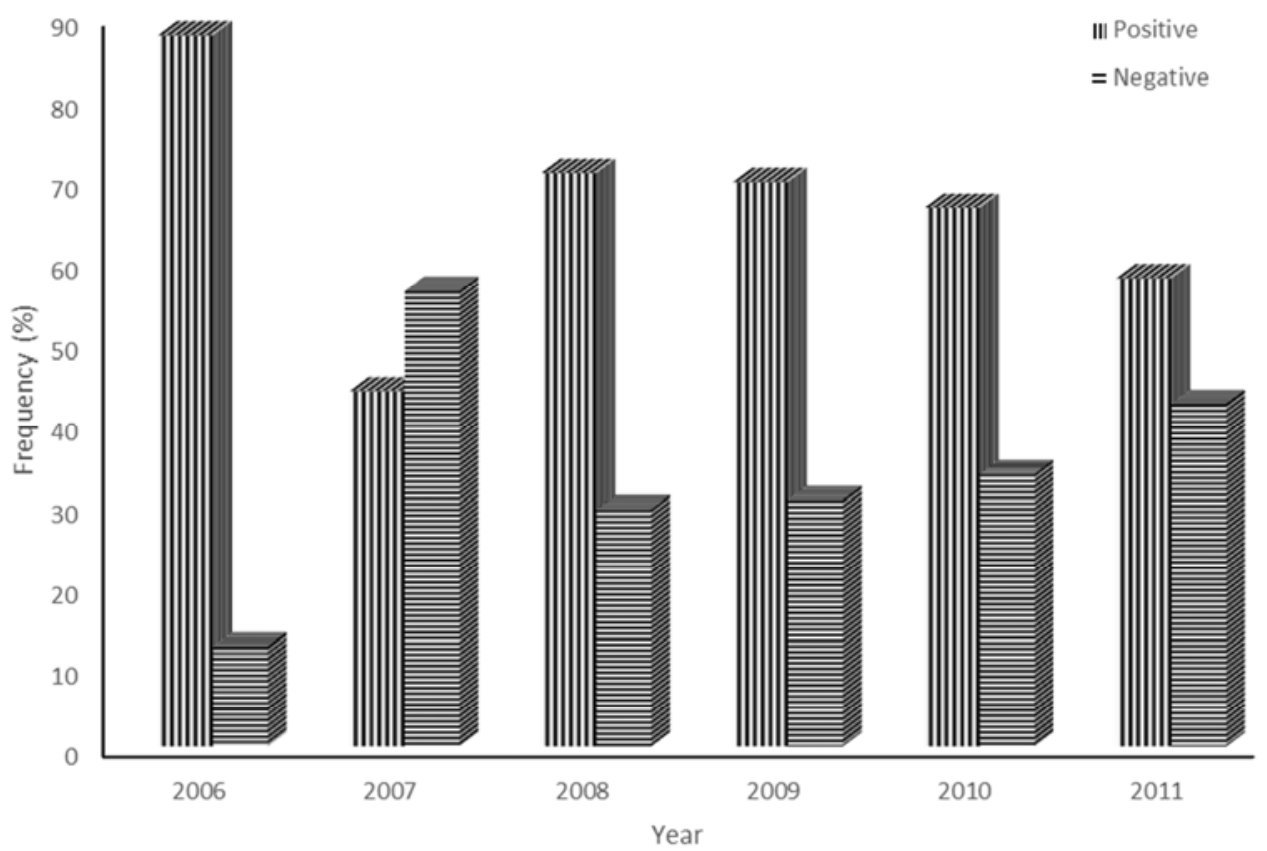

Figure 3. Distribution of Malaria by years. 


\subsection{Discussions}

The prevalence of malaria among neonates in this study is $61 \%$ and it is comparable to the prevalence rates between $61.1 \%$ and $71.4 \%$ as reported in previous studies in southern Nigeria [14-16] similar prevalence rates have been reported in endemic areas, with a high prevalence of malaria in the first three months of life. The occurrence of malaria in neonates have been attributed to congenital malaria as reported by Sotimehin [17]. The presence of parasites in the cord blood of $7-10 \%$ of newborns have been reported across Africa, sometimes without a symptomatic evidence of an active maternal infection, suggesting trans placental transfer of parasites to the fetus during pregnancy [18]. These high prevalence rates may result in childhood anemia and some other severe complications such as cerebral malaria and may also be potentially fatal to the infant $[19,20]$

About $2.94 \%$ of the patients had severe malaria $(\geq 3+$ parasitemia), an indication of prevalence of congenital malaria as documented in similar studies across Africa [20-22]. Malaria in pregnancy has been reported to have a significant association with the occurrence of congenital and neonatal malaria, especially when the pregnant mothers do not receive adequate care and treatment of malaria during the depressed immunity state which is characteristic of pregnancy [21].

Among the patients with severe malaria, the most associated conditions were septicemia and severe anaemia. This is similar to the reports of other studies, indicating that these symptoms could lead to impaired immune responses to other infections especially in neonates with immature immune systems [18-20].

The occurrence of malaria ranged from $56 \%$ to $86 \%$ between March and July, while there was a decline in occurrence from $70 \%$ to $18 \%$ between August and December. This is in agreement with the findings of related studies, showing that occurrence of malaria is significantly higher during the period of heavy rainfall in endemic countries of Sub-Saharan Africa [9, 16, 22].

There was a decline in malaria prevalence from $70.74 \%$ to $57.78 \%$ between 2008 and 2011 . This could be due to an improvement in the prevention and management of congenital malaria among pregnant women, based on the improved administration of the intermittent preventive treatment observed from the year 2005 in previous reports $[23,24]$. The decline in prevalence of malaria also coincides with the decline in child mortality recorded in the country.

\section{Conclusions}

The study is a confirmation of malaria in the newborn in South-South Nigeria, and calls for a high index of suspicion and an early screening of neonates for accurate diagnosis and prompt intervention that will prevent potential mortalities. Although malaria occurrence declined steadily from $70.7 \%$ to $57.7 \%$ between 2008 and 2011. There is a need to intensify efforts of preventing malaria in new born which will also contribute to the decline of child mortality a few weeks after birth.

\section{References}

[1] Oglala W. N. Malaria In: Azubuike JC Nkanginieme KEO editors. Paediatrics and Child health in a tropical region $2^{\text {nd }}$ ed Owerri. Nigeria African Education Services 1999: 596-604.

[2] World Health Organization (WHO) World Malaria Report 2011.

[3] Autino B, Corbett Y, Castelli F, Taramelli D. Pathogenesis of Malaria in Tissues and Blood. Med J Hem Infec Dis. 2012; 4(1): e2012061. doi: 10.4084/MJHID.2012.061.

[4] Falade C, Mokuolu O, Okafor H, Orogade A, Falade A, et al. (2007) Epidemiology of congenital malaria in Nigeria: a multi-centre study. Trop Med Int Health 12: 1279-1287.

[5] Mukhtar M (2007) The growing incidence of neonatal malaria--a situational review in developing countries. Niger J Med 16: 25-30

[6] Fischer PR, Nyirjesy P, Toko RM (1995) Congental malaria in twins west J med 163: 395-396.

[7] Fuscher PR (2003) MALARIA AND NEWBORN J TROP pediatr 49: 132-134.

[8] Menendez C, Mayor A. Congenital malaria: the least known consequence of malaria in pregnancy. Semin Fetal Neonatal Med, 2007; 12: 207-213.

[9] Okoli CA, Okolo SN, Collins JC. Plasmodium falciparum infection among neonates in the North Central Region of Nigeria. J Infect Dev Ctries 2013; 7(5): 265-371.

[10] Omalu ICJ, Mgbemena C, Mgbemena A, Ayanwale V, Olayemi IK, Lateef A, Chukwuemeka VI. Prevalence of Congenital Malaria in Minna, North Central Nigeria $J$. Trop Med 2012. 2 (12) 345 - 348. doi: 10.1155/2012/274142.

[11] Sowunmi A, Ilesanmi AO, Akindele JA, Abohweyere AEJ, Fawole AO, Falade CO, Oduola AMJ. Placental falciparum infection and outcome of pregnancy in Nigerian mothers from an endemic area. J Obstet Gynaecol, 1996; 16: 212-217.

[12] Falade C, Mokuolu O, Okafor H, Orogade A, Falade A, Adedoyin O, Oguonu T, Aisha M, Hamer DH, Callahan MV. Epidemiology of congenital malaria in Nigeria: a multi-centre study. Trop Med Int Health, 2007; 12: 1279-1287.

[13] Ndyomugyenyi R, Magnussen P. Chloroquine prophylaxis, iron/folic-acid supplementation or case management of malaria attacks in primigravidae in western Uganda: effects on congenital malaria and infant haemoglobin concentrations. Ann Trop Med Parasitol, 2007; 94: 759-770.

[14] Olasehinde GI, Ojurongbe DO, Akinjogunla OJ, Egwari LO, Adeyeba AO. Prevalence of Malaria and Predisposing Factors to Antimalarial Drug Resistance in Southwestern Nigeria. Res J of Para. 2015; 10 (3): 92-101.

[15] Abah AE, and Temple B. Prevalence of Malaria Parasite among Asymptomatic Primary School Children in Angiama Community, Bayelsa State, Nigeria. Trop Med Surg. 2015; 4: 1. http://dx.doi.org/10.4172/2329-9088.1000203. 
[16] Udoh EE, Oyo-ita AE, Odey FA, Eyong KI, Oringanje CM, Oduwole OA. Malariometric Indices among Nigerian children in a rural setting", Mal Res Treat, 2013; 7(1) 68-72.

[17] Sotimehin SA, Runsewe-Abiodun TA, Oladapo OT, Njokanma OF, Olanrewaju DM. Possible Risk Factors for Congenital Malaria at a Tertiary Care Hospital in Sagamu, Ogun State, Southwest Nigeria. Jour. Trop Ped, 2008; 8(2) 12 -15 .

[18] Alessandro U, Ubben D, Hamed K, Ceesay AJ, Okebe J, Taal M, Lama EK, Keita M, Koivogui L, Nahum A, Bojang K, Sonko AA, Lalya HF, Brabin B. Malaria in infants aged less than six months - is it an area of unmet medical need? Malaria Journal, 2012, 11: 400 - 405.

[19] Olasehinde GI, Ajayi AA, Taiwo SO, Adekeye BT, Adeyeba OA. Prevalence and Management of Falciparium Malaria Among Infants And Children In Ota, Ogun State, Southwestern Nigeria. Res J Paras, 2015; 10 (3): 92-101.

[20] Onankpa BO, Jiya NM, Achegbulu P, Airede KI. Congenital clinical malaria: incidence, management and outcome as seen in the Usman Danfodiyo University teaching hospital, Sokoto in Nigeria. Sah Med Jour. 2007; 10: 24-28.
[21] Lesko CR, Arguin PM, Newman RD. Congenital malaria in the United States: A review of cases from 1966-2005. Arch Pediatr Adolesc Med, 2006; 161: 1062-1067.

[22] Falade C, Mokuolu O, Okafor H, Orogade A, Falade A, Adedoyin O, Oguonu T, Aisha M, Hamer DH, Callahan MV. Epidemiology of congenital malaria in Nigeria: a multi-centre study. Trop Med Int Health, 2007; 12: 1279-1287.

[23] Mannir S. The Study of Intermittent Preventive Treatment (IPT) In The Control Of Malaia In Pregnancy At The Maternity Hospital Katsina, Nigeria. JORIND, 2014; 12 (1): 223-225.

[24] Bamgboye MA, Bayo SF, Olapeju O, Tolulope OS. Women in child-bearing age who are not currently pregnant are missed opportunities for malaria control in pregnancy: Evidence from 16 Local Government Areas of Nigeria. Jour Pub Epi, 2014; 6(1): 60-69. 